\title{
European Standardisation and its Impact on the Sealant Industry
}

The new European standard is currently an important issue in the sealant industry. Wolfram Fuchs, spokesperson for the technical working group of the German Sealant Industry Association (IVD), complained in a recent speech that the new CE mark does not offer the same high quality standards as the IVD.

Joint sealants are a construction product and are therefore subject to the requirements of the European Construction Products Regulation, which came into force on 24 April 2011 and is now due to be introduced into all the EU member states. Construction products are intended, by definition, to be a permanent feature of buildings.

The Construction Products Regulation forms the legal basis for defining the general usability requirements for products and for removing technical barriers to trade in the EU. However, the regulation only specifies objectives and does not describe how they can be achieved. These objectives are summarised in seven basic requirements:

- Mechanical resistance and stability

- Safety in case of fire

- Hygiene, health and the environment

- Safety and accessibility in use

- Protection against noise

- Energy economy and heat retention

- Sustainable use of natural resources These requirements form the basis for the creation of "harmonised" standards and, where appropriate, for identifying

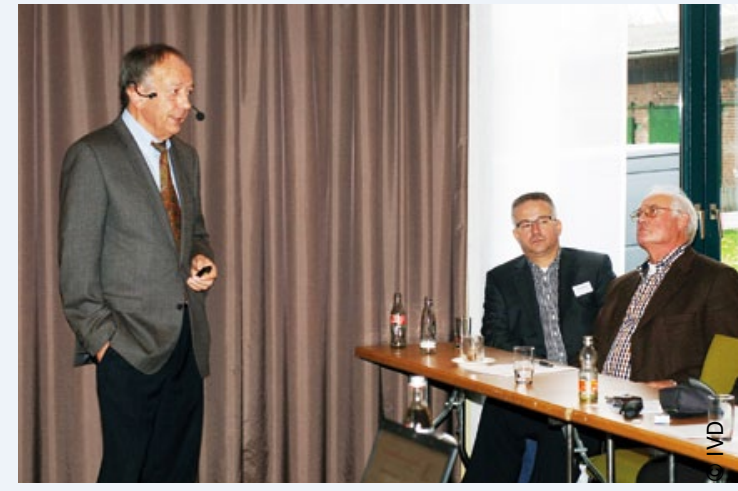

Wolfram Fuchs, spokesperson for the technical working group of the IVD. "The requirements of individual parts of DIN EN 15651 will have a negative impact on the quality of German sealants." the essential characteristics or threshold levels for the products in question. These standards will be drawn up by the European Committee for Standardisation (CEN) on the basis of a mandate from the European Commission. Manufacturers of products which are governed by these standards must produce a declaration of performance that describes the performance of the product in relation to the essential characteristics. This is a requirement for the allocation of the CE mark. Without a CE mark, products cannot be sold.

In order to be able to use the $\mathrm{CE}$ mark, every manufacturer and supplier of sealants must be able to provide a declaration of performance for every product on request.

In the field of sanitary joints, for example, this declaration of performance is based on the requirements of DIN EN 15651-3 and provides very limited information when compared with the higher quality standards of the IVD. Even a sanitary sealant in the highest class (XS1) does not necessarily meet the full requirements of the IVD.

For further information, please contact: IVD Industrieverband Dichtstoffe e.V., Postfach 180341, 40570 Düsseldorf, Germany

\section{Lohmann Founds Subsidiary in the Netherlands}

The Lohmann Tape Group can welcome a new member to its family. The name of the new subsidiary is Lohmann Netherlands B.V. and was created from parts of the Dutch company De Ridder B.V.

$D^{2}$ Ridder, a sales partner of Lohmann in the Netherlands for many years, has now placed all its adhesive tape activities in the hands of Lohm- ann. Lohmann's aim is to develop the existing relationships with its customers in the Netherlands and to acquire new customers. The company sees growth opportunities in the Building and Renewable Energies sector and more generally in the plastics processing industry. 